\title{
The Analysis of Size and Book-to-Market Ratio Effects in KRX under Good Deal Condition
}

\author{
Bongjoon Kim, Hankyung Lee, Jinsu Kim, and Insung Son
}

\begin{abstract}
This paper evaluates Size and book to market (BM) ratio effects in incomplete market by good deal (GD) bound. GD bound has the advantage of having no model specification error and reflecting diverse risk preference of marginal investors under incomplete market. We evaluate the performance of Size, BM ratio, and FF9 mimicking portfolios by GD bounds. As the result, Size mimicking portfolios show the increasing trend in upper GD bound but the decreasing trend in mean and lower GD bound as firm Size decreases. BM ratio mimicking portfolios show the decreasing trend of Median, upper and lower GD bound as BM ratio increases. Small Size and low BM ratio mimicking portfolios have relatively wider GD bound. These results implicate that Size effect and $\mathrm{BM}$ ratio effect are dependent on the selection among marginal investors that there exist infinitely under incomplete market. This also implies that market anomaly effect is due to not market inefficiency but model specification error of equilibrium approach.
\end{abstract}

Index Terms-Size effects, book to market (BM) ratio effects, stochastic discount factor, Euler equation, no arbitrage condition, good deal condition.

\section{INTRODUCTION}

Asset pricing by stochastic discount factor (SDF) is divided into parametric approach based on equilibrium model and non-parametric approach based on no arbitrage principle. Equilibrium model has the 'bad model' problem that theoretical SDF of equilibrium model is not among admissible SDF set of reference assets. Examples of these models are Sharpe, Lintner and Mossin's capital asset pricing model (CAPM) and Fama and French's 3 factor model, (for example, [1]-[4]). Non-parametric methods are based on no arbitrage principle which means both the law of one price and the positivity of SDF, (for example, [5]-[8]). Non-parametric approach extracts admissible SDF that has not any pricing error for reference assets. Therefore, no arbitrage approach is superior to equilibrium approach in terms of pricing error for reference assets.

In previous articles, Size and book to market (BM) ratio effects have usually been evaluated by parametric models that have mispricing of reference assets. So, we suggest nonparametric methods based on no arbitrage principle without bad model problem. Concretely, we evaluate the performance of Size and BM ratio mimicking portfolios by adding good deal (GD) condition (for example, [9]) to no arbitrage condition under incomplete market. Specific procedures are as follows.

In the first, we extract admissible SDFs that satisfy no

Manuscript received November 15, 2013; revised January 8, 2014.

The authors are with the Department of Business Administration, GyeongSang National University, 501 Jinju-daero, Jinju, Korea, 660-701 (e-mail: nlfu2@hanmail.net). arbitrage and no good deal condition for reference assets. In the second, we evaluate the performance of market anomaly mimicking portfolios by admissible SDFs. As the result, we derive maximum and minimum value of performance which we call GD upper bound and GD lower bound irrespectively. In the third, we diagnose market anomaly effect of Size, BM ratio, and FF9 mimicking portfolios by GD bound.

In equilibrium model, SDF has the economic meaning of inter-temporal marginal rate of substitution of marginal investor or representative agent. So, upper (lower) GD bound for some fund can be thought of as the performance assessment by the marginal investor who is the most (least) favorable for the fund. This implies that the marginal investor for upper (lower) GD bound tends to give high (low) marginal utility when the return of the mimicking portfolio is high and low (high) marginal utility when the return of the mimicking portfolio is low.

Our empirical results are as follows. The first is that the smaller Size mimicking portfolios show the increasing trend in upper GD bound but the decreasing trend in lower GD bound. The lower BM ratio portfolios show the increasing trend in both upper and lower GD bound. The second is that small Size portfolios show GD bound wider than large Size portfolios. Also, low BM ratio portfolios show the wider GD bound relative to high $\mathrm{BM}$ ratio portfolios. The wideness of GD bound implies that risk preference of marginal investors under incomplete market is different. As the result, the performance of market anomaly mimicking portfolios can be evaluated differently according to heterogeneous risk preference of marginal investors that there exist under incomplete market.

\section{LITERATURE REVIEW}

It is well known that most of parametric models based on equilibrium approach like CAPM do not explain Size and $\mathrm{BM}$ ratio effects as an empirical finding. Size (BM ratio) effect means that smaller (higher BM ratio) companies show higher risk-adjusted excess return in relative to larger (lower BM ratio) companies. These effects are called as a kind of market anomaly, as in [10]-[31].

But these parametric models are inevitably subject to 'bad model' problem, as in [32]. This causes the mispricing of reference assets which means assigning zero performance to passive strategies of reference portfolios, as in [6]. This causes performance measures based on equilibrium models not to be admissible in terms of [8]. This implies that portfolio performance evaluation can be significantly different according to parametric model.

Related this problem, Reference [5] suggested no arbitrage approach as non-parametric approach. They found the closed 
form solution of SDF that had minimum variance among admissible SDFs for reference assets. Based on this minimum variance SDF, Chen and Knez developed portfolio performance measure that has not bad model problem, as in [6]. They called this measure as an admissible performance measure because it assigns zero performance to any passive strategy that uninformed investors can construct from reference assets.

However, their method has limitation. There exist infinitely many admissible SDFs under incomplete market. Therefore, there exist infinitely many performance measures from one to one correspondence between admissible SDFs in [5] and admissible performance measures in [6]. This implies that performance evaluation can be different according to which kernel among admissible SDFs is used.

Basically, this ambiguity arises from incomplete market where the number of reference assets is smaller than the number of outcomes in probability space. If market becomes complete, there exists unique, admissible, and general SDF that can price all contingent claims in L2(p) space. But under incomplete market we do not know its concrete form and only know that the general SDF is among infinitely many admissible SDFs from projection theorem.

Admissible SDFs under incomplete market are equivalent in that they have not any pricing error for at least reference assets. The particular choice among admissible SDFs like the minimum-variance SDF provides only one performance measure among infinitely many performance measures from admissible SDFs. This implies that there is no guarantee that minimum-variance SDF is the same with the general SDF under complete market. In other words, minimum-variance SDF may not be admissible in the larger set of reference assets and therefore may lead to inference errors in performance measurement. This implies that another admissible SDF except minimum-variance SDF may have been more appropriate performance measure.

In this sense, reference [8] and [9] suggests to use all of admissible SDFs under incomplete market. As the result, they derived no arbitrage performance bound and no good deal bound irrespectively. Good deal opportunity means investment strategy more than times of market portfolio's Sharpe ratio. A prime example about high Sharpe Ratios is The Arbitrage Pricing Theory of [33]. Reference [5] established the duality between the maximum Sharpe Ratio from reference assets and the minimum variance of admissible SDFs. From this fact, no good deal opportunity in the market makes it possible to curtail the set of admissible SDFs by the restriction of volatility. Reference [9] derived portfolio performance bound by adding no good deal condition to no arbitrage condition. They called it as GD bound.

Besides, other researchers tried to derive more realistic performance bound by defining its own good deal condition. For example, reference [34] defined good deal opportunity using generalized Sharpe Ratio derived from the negative exponential utility function. Reference [35] defined good deal defined from certain utility class that has the smooth property. Reference [36] defined good deal based on gain-loss ratio.

\section{DAtA AND Methodology}

Reference [37] suggests the methodology to select reference portfolio for testing asset pricing models. This methodology has the advantage of minimizing measurement error and generating sufficient dispersion of returns over reference portfolios. For this purpose, Reference [37] applies cluster analysis as a statistical method. This is based on clustering analysis that individual stock should be highly correlated within group but have minimal correlation across groups. Reference [38] suggests that portfolios sorted according to industry are faithful to clustering criteria. But Reference [39] reported that Size and BM ratio mimicking portfolios do not represent enough risk exposures because within-group covariance of individual stock is not high. Therefore, we used industry portfolios as reference assets to measure excess performance of portfolio, as in [6], [40].

TABLE I: BASIC STATISTICS OF REFERENCE ASSETS

\begin{tabular}{cccc}
\hline Industry classification & Mean & Standard deviation & Sharpe ratio \\
\hline Food & 0.199 & 1.356 & 0.147 \\
Apparel & 0.178 & 1.829 & 0.097 \\
Paper and wood & 0.144 & 1.799 & 0.080 \\
Chemistry & 0.180 & 1.845 & 0.097 \\
Drug & 0.235 & 1.977 & 0.119 \\
Plastic & 0.204 & 2.029 & 0.101 \\
Fabricated Metals & 0.188 & 2.272 & 0.083 \\
Primary Metals & 0.184 & 2.367 & 0.078 \\
Machinery & 0.218 & 2.659 & 0.082 \\
Electronic & 0.180 & 2.395 & 0.075 \\
Medical & 0.106 & 2.698 & 0.039 \\
Electrical Equipment & 0.166 & 2.433 & 0.068 \\
Other Equipment & 0.238 & 2.564 & 0.093 \\
Transport Equipment & 0.259 & 2.369 & 0.109 \\
Construction & 0.169 & 2.876 & 0.059 \\
Retail & 0.201 & 2.213 & 0.091 \\
Broadcasting & 0.021 & 1.761 & 0.012 \\
Programming & 0.221 & 2.758 & 0.080 \\
Service & 0.189 & 2.132 & 0.089 \\
Holdings & 0.237 & 2.225 & 0.106 \\
\hline
\end{tabular}

Specifically, we select 91-day certificate of deposit as risk free asset and 20 numbers of industry portfolios in Korea Exchange as reference assets. We obtain monthly data from January 2001 to December 2012. The number of observations is 625. Basic statistics for reference assets are shown in Table I.

Market anomaly mimicking portfolios have the same sample period with reference assets. In the first, we constructed 10 numbers of Size mimicking portfolios and 10 numbers of $\mathrm{BM}$ ratio mimicking portfolios by ascending order. Also, to construct FF9 portfolios we grouped all stocks except financial firms in Korea Exchange into three portfolios every Size and BM by the ascending order. Basic statistics of mimicking portfolios are shown in Table II.

We obtain admissible SDFs under incomplete market by adding GD conditions to Euler equations for reference assets. GD conditions make the set of admissible SDFs curtailed. And then we estimate performance or risk adjusted excess return of Size, BM ratio, and FF9 mimicking portfolios. In the last, we derive the maximum and minimum value of performance. We call the first (the second) as the upper (lower) GD bound. 
TABLE II: BASIC STATISTICS OF MIMICKING PORTFOLIOS

\begin{tabular}{|c|c|c|c|}
\hline Size & Mean & Standard deviation & Sharpe ratio \\
\hline$B 1$ & 0.207 & 2.143 & 0.097 \\
\hline$B 2$ & 0.067 & 2.295 & 0.029 \\
\hline$B 3$ & 0.175 & 2.069 & 0.085 \\
\hline$B 4$ & 0.136 & 2.018 & 0.067 \\
\hline$B 5$ & 0.178 & 2.058 & 0.086 \\
\hline$B 6$ & 0.179 & 2.136 & 0.084 \\
\hline$B 7$ & 0.182 & 2.148 & 0.085 \\
\hline$B 8$ & 0.185 & 2.151 & 0.086 \\
\hline$B 9$ & 0.254 & 2.053 & 0.124 \\
\hline$B 10$ & 0.207 & 1.966 & 0.105 \\
\hline BM ratio & Mean & Standard deviation & Sharpe ratio \\
\hline$H 1$ & 0.239 & 2.262 & 0.106 \\
\hline$H 2$ & 0.263 & 2.311 & 0.114 \\
\hline$H 3$ & 0.180 & 1.943 & 0.093 \\
\hline$H 4$ & 0.209 & 2.040 & 0.103 \\
\hline H5 & 0.281 & 2.166 & 0.130 \\
\hline H6 & 0.164 & 2.044 & 0.080 \\
\hline$H 7$ & 0.190 & 2.078 & 0.092 \\
\hline$H 8$ & 0.158 & 2.097 & 0.075 \\
\hline$H 9$ & 0.162 & 1.958 & 0.083 \\
\hline$H 10$ & 0.177 & 2.029 & 0.087 \\
\hline FF9 & Mean & Standard deviation & Sharpe ratio \\
\hline$B 1 H 1$ & 0.148 & 2.392 & 0.062 \\
\hline$B 1 H 2$ & 0.157 & 2.187 & 0.072 \\
\hline$B 1 H 3$ & 0.130 & 2.049 & 0.063 \\
\hline$B 2 H 1$ & 0.159 & 2.443 & 0.065 \\
\hline$B 2 H 2$ & 0.163 & 2.137 & 0.076 \\
\hline$B 2 H 3$ & 0.180 & 1.840 & 0.098 \\
\hline$B 3 H 1$ & 0.222 & 2.037 & 0.109 \\
\hline$B 3 H 2$ & 0.226 & 2.000 & 0.113 \\
\hline B3H3 & 0.122 & 1.991 & 0.061 \\
\hline
\end{tabular}

Specifically, Euler's equation for reference assets is as follows.

$$
\begin{aligned}
& P_{t}=E\left[d_{t+1} \cdot\left(P_{t+1}+X_{t+1}\right) \mid \Omega_{t}\right] \\
& \Leftrightarrow 1=E\left[d_{t+1} \cdot R_{t+1} \mid \Omega_{t}\right] \\
& \Leftrightarrow 0=E\left[d_{t+1} \cdot R_{t+1}-1 \mid \Omega_{t}\right]
\end{aligned}
$$

where $P t$ is the price vector of reference assets at period $t$ under static model. $P t+1$ and $X t+1$ is price and dividend vector at terminal period $t+1 . d t+1$ is $\mathrm{SDF}$ at terminal period. $\Omega t$ is the information set available at period t.

Econometrically, incomplete market means that the number of sample period is larger than the number of reference assets. In this case, there exist infinitely many solutions of SDF satisfying Euler equations because Euler equation system is under-identified system. GD condition makes it possible to tighten solutions of SDF. Specifically, portfolio performance under no arbitrage and no good deal condition can be estimated as follows.

$$
\begin{array}{cc}
\text { Upper GD bound } & \bar{\alpha}=\operatorname{Max}\left(E\left[d_{t+1} \cdot R_{t+1}\right]\right)-1 \\
\text { Lower GD bound } & \underline{\alpha}=\operatorname{Min}\left(E\left[d_{t+1} \cdot R_{t+1}\right]\right)-1 \\
\text { s. t. (1) } 1_{N}=E\left[d_{t+1} \cdot R_{t+1}\right], d_{t+1}>0 \text {, (2) } \sigma\left(d_{t+1}\right) \leq \Delta h / R_{f}
\end{array}
$$

where $\bar{\alpha}(\underline{\alpha})$ is maximum (minimum) performance estimate of mimicking portfolios. $\sigma\left(d_{t+1}\right)$ is the volatility of SDF. $h$ is the maximum sharp ratio on efficient frontier from reference assets $(h=0.194) . \Delta$ is the multiplier of maximum sharp ratio.

Constraint (1) is no arbitrage condition and Constraint (2) is GD condition. Because the multiplier $\Delta$ of GD condition is arbitrary, we estimated GD bounds with differentiating $\Delta$ from 0.9 to 2 . We define the following measures from estimated GD bounds.

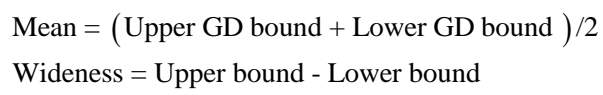

If Size effects exist in Korea equity market, smaller (higher) portfolios must have higher estimates of GD bound than bigger (lower) portfolios. Reference [8] suggests portfolio dominance criteria by admissible SDFs. According to them, Upper (Lower) bound can be thought as the performance assessment of the most (least) favorable marginal investor class. Therefore, if lower GD bound of some portfolio is above upper GD bound of another portfolio, we can say that the first portfolio is absolutely preferred to the second portfolio by all marginal investors under incomplete market. This can be the critical evidence of market anomaly effect because we can assure that the unique but unobservable marginal investor under complete market will prefer the first to the second. In the same logic, positive (negative) lower (upper) GD bound indicates that all marginal investors evaluate target portfolio positively (negatively). Also, positive (negative) upper (lower) GD bound indicates that at least one marginal investor values target portfolio favorably (unfavorably). We analyze market anomaly effect of mimicking portfolios using the previous dominance criteria.

\section{RESUlts}

In this section, we use median, upper bound, lower bound, wideness of GD bound to analyze market anomaly effects of Size, BM, FF9 mimicking portfolios under incomplete market.

The estimates of Size mimicking portfolios are shown in Table III.

In Table III(a), median of $B 9(7.4 \%)$ is the highest and mean of $B 2(-10 \% \sim-12.1 \%)$ is the lowest. The others except for $B 2$ and $B 4$ have positive median. Therefore, many marginal investors value the larger Size portfolios favorably relative to the smaller Size portfolios. This implies that there is not Size effect in KRX market in terms of median GD bound.

In Table III(b), upper GD bound of $B 1$ is the highest over $\Delta$. This implies that the most favorable investor class values $B 1$ the most favorably. It is observed that the smaller Size portfolios are evaluated more favorably than the larger Size portfolios. Therefore, there exist Size effects in KRX market in terms of upper GD bound. Signs of upper GD bounds are positive. This implies that all of Size portfolios have at least one marginal investor as their client.

In Table III(c), $B 9$ has the highest and positive lower GD bound when the value of $\Delta$ is less than 1.1. Positive lower GD bound indicates that every marginal investor under incomplete market value $B 9$ favorably. Approximately lower GD bounds of big Size portfolios are higher than small Size. This implies that there is not Size effect in KRX market in terms of lower GD bound.

In summary, Size mimicking portfolios show the increasing trend in upper GD bound but the decreasing trend in mean and lower GD bound as firm Size decreases. The first implies that there exists Size effect but the second implies 
that there is little Size effect or its adverse effect in KRX market. This implies that Size effect is dependent on the selection of marginal investor under incomplete market and may be due to model specification error.

In Table III(d), GD bound becomes wider as firm Size decreases. This implicates that marginal investors under incomplete market have more heterogeneous valuation about small Size portfolios relative to large Size portfolios. This implies that small firm effect is dependent on the selection of marginal investor under incomplete market. This implies that small firm effect may be due to model specification error rather than market anomaly effect.

TABLE III: THE ESTIMATES OF SIZE MIMICKING PORTFOLIOS

(a) Median

\begin{tabular}{ccccccccc}
\hline$\Delta$ & 1 & 1.05 & 1.1 & 1.2 & 1.3 & 1.5 & 1.8 & 2 \\
\hline$B 1$ & 0.035 & 0.035 & 0.035 & 0.035 & 0.035 & 0.035 & 0.035 & 0.035 \\
$B 2$ & -0.100 & -0.100 & -0.101 & -0.103 & -0.103 & -0.110 & -0.117 & -0.121 \\
$B 3$ & 0.007 & 0.007 & 0.007 & 0.007 & 0.007 & 0.007 & 0.007 & 0.007 \\
$B 4$ & -0.038 & -0.038 & -0.038 & -0.038 & -0.038 & -0.038 & -0.037 & -0.037 \\
$B 5$ & 0.012 & 0.012 & 0.012 & 0.012 & 0.012 & 0.012 & 0.012 & 0.012 \\
$B 6$ & 0.018 & 0.018 & 0.018 & 0.018 & 0.018 & 0.018 & 0.018 & 0.018 \\
$B 7$ & 0.011 & 0.012 & 0.012 & 0.012 & 0.012 & 0.014 & 0.016 & 0.017 \\
$B 8$ & 0.018 & 0.018 & 0.018 & 0.018 & 0.018 & 0.018 & 0.018 & 0.018 \\
$B 9$ & 0.074 & 0.074 & 0.074 & 0.074 & 0.074 & 0.074 & 0.074 & 0.074 \\
$B 10$ & 0.034 & 0.034 & 0.034 & 0.034 & 0.034 & 0.035 & 0.035 & 0.036 \\
\hline
\end{tabular}

(b) Upper bound

\begin{tabular}{ccccccccc}
\hline$\Delta$ & 1 & 1.05 & 1.1 & 1.2 & 1.3 & 1.5 & 1.8 & 2 \\
\hline$B 1$ & 0.150 & 0.174 & 0.195 & 0.233 & 0.229 & 0.329 & 0.415 & 0.469 \\
$B 2$ & 0.016 & 0.040 & 0.060 & 0.094 & 0.091 & 0.178 & 0.251 & 0.296 \\
$B 3$ & 0.093 & 0.110 & 0.126 & 0.154 & 0.152 & 0.226 & 0.290 & 0.330 \\
$B 4$ & 0.038 & 0.054 & 0.068 & 0.093 & 0.090 & 0.157 & 0.213 & 0.249 \\
$B 5$ & 0.086 & 0.101 & 0.115 & 0.140 & 0.137 & 0.202 & 0.258 & 0.293 \\
$B 6$ & 0.083 & 0.097 & 0.108 & 0.130 & 0.128 & 0.184 & 0.233 & 0.264 \\
$B 7$ & 0.088 & 0.104 & 0.118 & 0.144 & 0.141 & 0.208 & 0.265 & 0.300 \\
$B 8$ & 0.076 & 0.088 & 0.099 & 0.118 & 0.116 & 0.167 & 0.211 & 0.238 \\
$B 9$ & 0.127 & 0.138 & 0.148 & 0.166 & 0.164 & 0.211 & 0.250 & 0.275 \\
$B 10$ & 0.085 & 0.095 & 0.104 & 0.121 & 0.119 & 0.162 & 0.198 & 0.220 \\
\hline
\end{tabular}

(c) Lower bound

\begin{tabular}{ccccccccc}
\hline$\Delta$ & 1 & 1.05 & 1.1 & 1.2 & 1.3 & 1.5 & 1.8 & 2 \\
\hline$B 1$ & -0.080 & -0.103 & -0.124 & -0.162 & -0.159 & -0.259 & -0.345 & -0.400 \\
$B 2$ & -0.216 & -0.240 & -0.261 & -0.300 & -0.296 & -0.397 & -0.484 & -0.538 \\
$B 3$ & -0.078 & -0.095 & -0.111 & -0.139 & -0.137 & -0.211 & -0.275 & -0.316 \\
$B 4$ & -0.114 & -0.129 & -0.143 & -0.168 & -0.166 & -0.232 & -0.288 & -0.323 \\
$B 5$ & -0.062 & -0.077 & -0.091 & -0.115 & -0.113 & -0.178 & -0.233 & -0.268 \\
$B 6$ & -0.047 & -0.061 & -0.073 & -0.094 & -0.092 & -0.149 & -0.198 & -0.228 \\
$B 7$ & -0.065 & -0.081 & -0.095 & -0.119 & -0.117 & -0.180 & -0.233 & -0.267 \\
$B 8$ & -0.040 & -0.052 & -0.063 & -0.082 & -0.081 & -0.132 & -0.175 & -0.202 \\
$B 9$ & 0.020 & 0.009 & 0.000 & -0.018 & -0.016 & -0.063 & -0.102 & -0.127 \\
$B 10$ & -0.016 & -0.027 & -0.036 & -0.052 & -0.051 & -0.093 & -0.127 & -0.148 \\
\hline
\end{tabular}

(d) Wideness

\begin{tabular}{ccccccccc}
\hline$\Delta$ & 1 & 1.05 & 1.1 & 1.2 & 1.3 & 1.5 & 1.8 & 2 \\
\hline$B 1$ & 0.230 & 0.277 & 0.320 & 0.395 & 0.388 & 0.588 & 0.760 & 0.869 \\
$B 2$ & 0.232 & 0.280 & 0.321 & 0.394 & 0.387 & 0.575 & 0.734 & 0.834 \\
$B 3$ & 0.170 & 0.206 & 0.237 & 0.293 & 0.288 & 0.437 & 0.565 & 0.646 \\
$B 4$ & 0.152 & 0.183 & 0.211 & 0.261 & 0.256 & 0.388 & 0.501 & 0.573 \\
$B 5$ & 0.148 & 0.179 & 0.206 & 0.255 & 0.250 & 0.380 & 0.491 & 0.561 \\
$B 6$ & 0.130 & 0.157 & 0.181 & 0.224 & 0.220 & 0.333 & 0.431 & 0.492 \\
$B 7$ & 0.154 & 0.185 & 0.213 & 0.262 & 0.258 & 0.388 & 0.498 & 0.567 \\
$B 8$ & 0.116 & 0.141 & 0.162 & 0.200 & 0.197 & 0.299 & 0.386 & 0.440 \\
$B 9$ & 0.107 & 0.129 & 0.149 & 0.184 & 0.181 & 0.274 & 0.353 & 0.402 \\
$B 10$ & 0.101 & 0.122 & 0.140 & 0.173 & 0.170 & 0.255 & 0.325 & 0.369 \\
\hline
\end{tabular}

GD bound estimates of BM ratio mimicking portfolios are shown in Table IV.

In Table IV(a), median of H5 $(7.5 \% \sim 8.6 \%)$ is the highest and median of $H 6(-2.4 \% \sim-2.7 \%)$ is the lowest. The others except for $H 6$ and $H 8$ have positive median. This indicates that most of marginal investors evaluate $\mathrm{BM}$ ratio mimicking portfolios favorably in terms of median.

In Table IV(b), the highest GD upper bound of Size mimicking portfolios is different according to $\Delta . H 5$ has the highest value when the value of $\Delta$ is less than 1.2 and $H 1$ has the highest value when the value of $\Delta$ is more than 1.2. H6 has the lowest value over all values of $\Delta$.

TABLE IV: THE ESTIMATES OF BM RATIO MIMICKING PORTFOLIOS

\begin{tabular}{ccccccccc} 
(a) Median \\
\hline$\Delta$ & 1 & 1.05 & 1.1 & 1.2 & 1.3 & 1.5 & 1.8 & 2 \\
\hline$H 1$ & 0.064 & 0.064 & 0.064 & 0.063 & 0.063 & 0.063 & 0.064 & 0.064 \\
$H 2$ & 0.057 & 0.057 & 0.057 & 0.055 & 0.055 & 0.055 & 0.055 & 0.056 \\
$H 3$ & 0.009 & 0.009 & 0.009 & 0.006 & 0.006 & 0.006 & 0.006 & 0.007 \\
$H 4$ & 0.026 & 0.026 & 0.026 & 0.023 & 0.023 & 0.023 & 0.023 & 0.022 \\
$H 5$ & 0.082 & 0.082 & 0.082 & 0.075 & 0.075 & 0.076 & 0.076 & 0.077 \\
$H 6$ & -0.024 & -0.024 & -0.024 & -0.028 & -0.028 & -0.028 & -0.027 & -0.027 \\
$H 7$ & 0.015 & 0.015 & 0.015 & 0.013 & 0.013 & 0.013 & 0.013 & 0.014 \\
$H 8$ & -0.005 & -0.005 & -0.005 & -0.008 & -0.008 & -0.008 & -0.007 & -0.007 \\
$H 9$ & 0.002 & 0.002 & 0.002 & 0.003 & 0.003 & 0.003 & 0.004 & 0.004 \\
$H 10$ & 0.015 & 0.015 & 0.015 & 0.012 & 0.012 & 0.013 & 0.014 & 0.014 \\
\hline
\end{tabular}

(b) Upper bound

\begin{tabular}{ccccccccc}
\hline$\Delta$ & 1 & 1.05 & 1.1 & 1.2 & 1.3 & 1.5 & 1.8 & 2 \\
\hline$H 1$ & 0.087 & 0.139 & 0.168 & 0.208 & 0.245 & 0.307 & 0.388 & 0.438 \\
$H 2$ & 0.077 & 0.122 & 0.148 & 0.182 & 0.214 & 0.269 & 0.341 & 0.386 \\
$H 3$ & 0.028 & 0.071 & 0.096 & 0.127 & 0.157 & 0.209 & 0.278 & 0.320 \\
$H 4$ & 0.045 & 0.090 & 0.115 & 0.149 & 0.180 & 0.235 & 0.305 & 0.349 \\
$H 5$ & 0.102 & 0.146 & 0.171 & 0.195 & 0.225 & 0.277 & 0.346 & 0.388 \\
$H 6$ & -0.006 & 0.035 & 0.058 & 0.086 & 0.115 & 0.164 & 0.229 & 0.269 \\
$H 7$ & 0.034 & 0.078 & 0.103 & 0.136 & 0.167 & 0.221 & 0.292 & 0.335 \\
$H 8$ & 0.015 & 0.061 & 0.087 & 0.122 & 0.155 & 0.212 & 0.286 & 0.332 \\
$H 9$ & 0.023 & 0.070 & 0.097 & 0.137 & 0.171 & 0.229 & 0.306 & 0.353 \\
$H 10$ & 0.035 & 0.080 & 0.106 & 0.141 & 0.173 & 0.229 & 0.302 & 0.347 \\
\hline
\end{tabular}

(c) Lower bound

\begin{tabular}{ccccccccc}
\hline$\Delta$ & 1 & 1.05 & 1.1 & 1.2 & 1.3 & 1.5 & 1.8 & 2 \\
\hline$H 1$ & 0.042 & -0.010 & -0.039 & -0.083 & -0.119 & -0.180 & -0.260 & -0.309 \\
$H 2$ & 0.037 & -0.008 & -0.033 & -0.072 & -0.104 & -0.158 & -0.230 & -0.275 \\
$H 3$ & -0.009 & -0.052 & -0.077 & -0.114 & -0.144 & -0.197 & -0.265 & -0.307 \\
$H 4$ & 0.006 & -0.039 & -0.064 & -0.102 & -0.134 & -0.188 & -0.260 & -0.304 \\
$H 5$ & 0.062 & 0.018 & -0.007 & -0.044 & -0.075 & -0.126 & -0.193 & -0.235 \\
$H 6$ & -0.042 & -0.083 & -0.106 & -0.141 & -0.170 & -0.219 & -0.284 & -0.324 \\
$H 7$ & -0.004 & -0.048 & -0.073 & -0.111 & -0.142 & -0.195 & -0.265 & -0.308 \\
$H 8$ & -0.026 & -0.072 & -0.098 & -0.138 & -0.171 & -0.227 & -0.300 & -0.345 \\
$H 9$ & -0.019 & -0.066 & -0.093 & -0.131 & -0.165 & -0.223 & -0.299 & -0.345 \\
$H 10$ & -0.006 & -0.051 & -0.077 & -0.116 & -0.149 & -0.203 & -0.275 & -0.319 \\
\hline
\end{tabular}

(d) Wideness

\begin{tabular}{ccccccccc}
\hline$\Delta$ & 1 & 1.05 & 1.1 & 1.2 & 1.3 & 1.5 & 1.8 & 2 \\
\hline$H 1$ & 0.046 & 0.149 & 0.207 & 0.291 & 0.364 & 0.487 & 0.648 & 0.746 \\
$H 2$ & 0.040 & 0.130 & 0.181 & 0.254 & 0.318 & 0.427 & 0.571 & 0.660 \\
$H 3$ & 0.038 & 0.124 & 0.173 & 0.240 & 0.301 & 0.406 & 0.543 & 0.627 \\
$H 4$ & 0.039 & 0.128 & 0.179 & 0.251 & 0.314 & 0.423 & 0.565 & 0.653 \\
$H 5$ & 0.039 & 0.128 & 0.179 & 0.240 & 0.300 & 0.404 & 0.539 & 0.623 \\
$H 6$ & 0.036 & 0.118 & 0.165 & 0.227 & 0.285 & 0.383 & 0.513 & 0.593 \\
$H 7$ & 0.039 & 0.126 & 0.176 & 0.247 & 0.309 & 0.416 & 0.557 & 0.643 \\
$H 8$ & 0.041 & 0.133 & 0.186 & 0.260 & 0.326 & 0.439 & 0.586 & 0.677 \\
$H 9$ & 0.042 & 0.136 & 0.190 & 0.268 & 0.336 & 0.452 & 0.604 & 0.699 \\
$H 10$ & 0.040 & 0.131 & 0.184 & 0.257 & 0.322 & 0.432 & 0.577 & 0.666 \\
\hline
\end{tabular}

In Table IV(c), $H 5$ has the highest lower GD bound whose sign is positive when the value of $\Delta$ is less than 1.05 . Positive lower bound indicates that every investors value H5 favorably. On the other hand, H6 has the lowest value over most values of $\Delta$. Roughly, BM ratio mimicking portfolios show the decreasing trend of Median, Upper and Lower GD 
bound as BM ratio increases. This implies that there is little $\mathrm{BM}$ ratio effect or there is its adverse effect in KRX market.

In Table IV(d), BM ratio mimicking portfolios show little difference in terms of wideness of GD bound. This implies that marginal investors under incomplete market have relatively homogeneous valuation about BM ratio mimicking portfolios.

The estimates of FF9 mimicking portfolios are shown in Table V.

In Table $\mathrm{V}(\mathrm{a})$, median of $B 3 H 1(4.0 \% \sim 4.3 \%)$ is the highest and median of $B 3 H 3(-3.9 \% \sim-4.0 \%)$ is the lowest. Therefore the largest Size and the lowest BM ratio portfolio shows the best performance in terms of median.

TABLE V: THE ESTIMATES OF FF9 MIMICKING PORTFOLIOS

\begin{tabular}{ccccccccc} 
(a) Median \\
\hline$\Delta$ & 1 & 1.05 & 1.1 & 1.2 & 1.3 & 1.5 & 1.8 & 2 \\
\hline$B 1 H 1$ & -0.006 & -0.007 & -0.007 & -0.007 & -0.007 & -0.007 & -0.007 & -0.007 \\
$B 1 H 2$ & -0.009 & -0.009 & -0.009 & -0.009 & -0.009 & -0.009 & -0.009 & -0.009 \\
$B 1 H 3$ & -0.016 & -0.015 & -0.015 & -0.016 & -0.018 & -0.023 & -0.030 & -0.034 \\
$B 2 H 1$ & -0.016 & -0.014 & -0.014 & -0.014 & -0.014 & -0.014 & -0.014 & -0.014 \\
$B 2 H 2$ & -0.012 & -0.010 & -0.010 & -0.010 & -0.010 & -0.010 & -0.010 & -0.010 \\
$B 2 H 3$ & 0.028 & 0.028 & 0.029 & 0.030 & 0.030 & 0.032 & 0.034 & 0.036 \\
$B 3 H 1$ & 0.040 & 0.040 & 0.040 & 0.040 & 0.040 & 0.041 & 0.042 & 0.043 \\
$B 3 H 2$ & 0.027 & 0.027 & 0.027 & 0.027 & 0.027 & 0.027 & 0.027 & 0.027 \\
$B 3 H 3$ & -0.040 & -0.040 & -0.040 & -0.040 & -0.040 & -0.040 & -0.040 & -0.039 \\
\hline
\end{tabular}

(b) Upper bound

\begin{tabular}{ccccccccc}
\hline$\Delta$ & 1 & 1.05 & 1.1 & 1.2 & 1.3 & 1.5 & 1.8 & 2 \\
\hline$B 1 H 1$ & -0.004 & 0.073 & 0.108 & 0.160 & 0.203 & 0.275 & 0.371 & 0.431 \\
$B 1 H 2$ & -0.005 & 0.054 & 0.082 & 0.123 & 0.156 & 0.214 & 0.290 & 0.337 \\
$B 1 H 3$ & -0.009 & 0.054 & 0.084 & 0.127 & 0.160 & 0.213 & 0.282 & 0.324 \\
$B 2 H 1$ & -0.011 & 0.043 & 0.068 & 0.106 & 0.136 & 0.188 & 0.257 & 0.300 \\
$B 2 H 2$ & -0.010 & 0.035 & 0.055 & 0.084 & 0.108 & 0.149 & 0.203 & 0.237 \\
$B 2 H 3$ & 0.031 & 0.080 & 0.104 & 0.138 & 0.165 & 0.212 & 0.273 & 0.310 \\
$B 3 H 1$ & 0.041 & 0.078 & 0.095 & 0.120 & 0.141 & 0.176 & 0.222 & 0.250 \\
$B 3 H 2$ & 0.029 & 0.065 & 0.082 & 0.107 & 0.127 & 0.161 & 0.206 & 0.234 \\
$B 3 H 3$ & -0.037 & 0.017 & 0.042 & 0.080 & 0.110 & 0.162 & 0.231 & 0.273 \\
\hline
\end{tabular}

(c) Lower bound

\begin{tabular}{ccccccccc}
\hline$\Delta$ & 1 & 1.05 & 1.1 & 1.2 & 1.3 & 1.5 & 1.8 & 2 \\
\hline$B 1 H 1$ & -0.007 & -0.087 & -0.122 & -0.175 & -0.217 & -0.290 & -0.386 & -0.445 \\
$B 1 H 2$ & -0.013 & -0.073 & -0.100 & -0.142 & -0.175 & -0.233 & -0.308 & -0.354 \\
$B 1 H 3$ & -0.022 & -0.084 & -0.114 & -0.159 & -0.196 & -0.259 & -0.341 & -0.393 \\
$B 2 H 1$ & -0.021 & -0.072 & -0.097 & -0.135 & -0.165 & -0.217 & -0.286 & -0.328 \\
$B 2 H 2$ & -0.014 & -0.055 & -0.075 & -0.105 & -0.129 & -0.170 & -0.224 & -0.257 \\
$B 2 H 3$ & 0.025 & -0.024 & -0.046 & -0.078 & -0.104 & -0.148 & -0.204 & -0.238 \\
$B 3 H 1$ & 0.039 & 0.001 & -0.016 & -0.040 & -0.060 & -0.094 & -0.137 & -0.164 \\
$B 3 H 2$ & 0.026 & -0.010 & -0.027 & -0.052 & -0.072 & -0.106 & -0.151 & -0.179 \\
$B 3 H 3$ & -0.043 & -0.097 & -0.123 & -0.160 & -0.190 & -0.242 & -0.310 & -0.352 \\
\hline
\end{tabular}

(d) Wideness

\begin{tabular}{ccccccccc}
\hline$\Delta$ & 1 & 1.05 & 1.1 & 1.2 & 1.3 & 1.5 & 1.8 & 2 \\
\hline$B 1 H 1$ & 0.003 & 0.160 & 0.230 & 0.335 & 0.420 & 0.565 & 0.757 & 0.876 \\
$B 1 H 2$ & 0.008 & 0.126 & 0.182 & 0.264 & 0.332 & 0.447 & 0.598 & 0.691 \\
$B 1 H 3$ & 0.013 & 0.138 & 0.199 & 0.286 & 0.356 & 0.472 & 0.623 & 0.717 \\
$B 2 H 1$ & 0.011 & 0.115 & 0.165 & 0.240 & 0.301 & 0.406 & 0.543 & 0.628 \\
$B 2 H 2$ & 0.003 & 0.090 & 0.130 & 0.189 & 0.236 & 0.319 & 0.427 & 0.494 \\
$B 2 H 3$ & 0.006 & 0.104 & 0.150 & 0.216 & 0.269 & 0.360 & 0.477 & 0.548 \\
$B 3 H 1$ & 0.002 & 0.077 & 0.111 & 0.161 & 0.201 & 0.270 & 0.359 & 0.414 \\
$B 3 H 2$ & 0.003 & 0.076 & 0.109 & 0.158 & 0.199 & 0.267 & 0.357 & 0.413 \\
$B 3 H 3$ & 0.006 & 0.114 & 0.165 & 0.240 & 0.301 & 0.405 & 0.541 & 0.625 \\
\hline
\end{tabular}

In Table $\mathrm{V}(\mathrm{b})$, upper GD bounds are dependent on values of $\Delta$. Specifically, $B 3 H 1$ shows the highest value when the value of $\triangle$ is $1 . B 2 H 3$ shows the highest value when the value of $\Delta$ is $1.05 . B 1 H 1$ shows the highest value when the value of $\Delta$ is more than 1.1. This makes it hard to make a robust conclusion.

In Table V(c), B3H1 shows the highest lower GD bound when $\Delta$ is less than 1.05 . Its positive sign indicates that all of marginal investors under incomplete market value $B 3 H 1$ favorably. The lowest lower GD bound is also dependent on $\Delta$. Specifically, $B 3 H 3$ shows the lowest value when the value of $\Delta$ is less than 1.1. $B 1 H 1$ shows the lowest value when the value of $\Delta$ is over 1.1 .

In Table $\mathrm{V}(\mathrm{d}), B 1 H 1$ has the widest bound except when $\Delta$ is $1 . B 3 H 2$ has the narrowest bound. Approximately, small Size and low BM mimicking portfolios have GD bound wider than the other portfolios. This implies that marginal investors in KRX market have relatively more heterogeneous valuation about small Size and low BM ratio portfolios.

\section{CONCLUSION}

We extracted admissible SDFs under no arbitrage and no GD condition and estimated GD bounds as performance bounds about Size, BM ratio and FF9 mimicking portfolios in KRX. Our conclusion is as follows.

In the first, Size mimicking portfolios show the increasing trend in upper GD bound but the decreasing trend in mean and lower GD bound as firm Size decreases. The first implies that there exists Size effect but the second implies that there is little Size effect or its adverse effect in KRX market.

In the second, BM ratio mimicking portfolios show the decreasing trend of Median, Upper and Lower GD bound as $\mathrm{BM}$ ratio increases. This implies that there is little BM ratio effect or its adverse effect.

In the third, the wideness of GD bound implies that performance of mimicking portfolios can be different according to heterogeneous risk preference of marginal investors under incomplete market. We found that small Size and low BM ratio mimicking portfolios have GD bound wider than the other portfolios. This is the same with FF9 mimicking portfolios.

From the previous empirical results, we conclude that Size effect and BM ratio effect is dependent on the selection of marginal investor under incomplete market. This implies that market anomaly effect is due to not market inefficiency but model specification error of equilibrium approach.

\section{REFERENCES}

[1] W. F. Sharpe, "Capital asset prices: a theory of market equilibrium under conditions of risk," Journal of Finance, vol. 19, pp. 425-442, 1964.

[2] J. Lintner, "The valuation of risk assets and the selection of risky investments in stock portfolios and capital budgets," Review of Economics and Statistics, vol. 47, pp. 13-37, 1965.

[3] J. Mossin, "Equilibrium in a capital asset market," Econometrica, vol. 34, pp. 768-783, 1966.

[4] E. F. Fama and K. R. French, "Common risk factors in the returns on stocks and bonds," Journal of Financial Economics, vol. 33 pp. 2-56, 1993.

[5] L. P. Hansen and R. Jagannathan, "Implications of security market data for models of dynamic economies," Journal of Political Economy, vol. 99, pp. 225-262, 1991.

[6] Z. Chen and P. J. Knez, "Portfolio performance measurement: Theory and application," Review of Financial Studies, vol. 9, pp. 511-555, 1996.

[7] H. Farnsworth, W. E. Ferson, D. Jackson, and S. Todd, "Performance evaluation with stochastic discount factors," Journal of Business, vol. 75, pp. 473-503, 2002.

[8] D. H. Ahn, H. H. Cao, and S. Chretien, "Portfolio performance measurement: a no arbitrage bounds approach," European Financial Management, vol. 15, pp. 298-339, 2009. 
[9] J. H. Cochrane and J. S. Requejo, "Beyond arbitrage: 'good-deal' asset price bounds in incomplete markets," Journal of Political Economy, vol. 108, pp. 79-119, 2000.

[10] R. W. Banz, "The relationship between return and market value of common stock," Journal of Financial Economics, vol. 9, no. 3-18. pp. 103-126, 1981

[11] M. R. Reinganum, "Misspecification of capital asset pricing, Empirical anomalies based on earing's yields and market values," Journal of Financial Economics, vol. 9, pp. 19-46, 1981.

[12] S. Basu, "The relationship between earnings yield, market value, and return for NYSE common stocks," Journal of Financial Economics, vol. 12, pp. 129-156, 1983.

[13] D. B. Keim, "Size-related anomalies and Stock return seasonality," Journal of Financial Economics, vol. 12, pp. 13-32, 1983.

[14] B. Rosenberg, K. Reid, and R. Lanstein, "Persuasive evidence of market inefficiency," Journal of Portfolio Management, vol. 11, pp. 9-17, 1985

[15] L. C. Chan, Y. Hamao, and J. Lakonishok, "Fundamentals and stock returns in Japan," Journal of Finance, vol. 46, pp. 1739-1764, 1991.

[16] E. F. Fama and K, R. French, "The cross-section of expected stock returns," Journal of Finance, vol. 47, pp. 427-465, 1992.

[17] W. S. Yoon, S. H. Sunwoo, H. S. Kang, S. W. Kim, H. S. Jang, and H. S. Choi, "Characteristics of Stock Price Movements and Seasonal Anomalies in Korean Stock Market," Korea Journal of Financial Studies, vol. 17, pp. 121-166, 1994.

[18] J. Lakonishok, A. Shleifer, and R. W. Vishny, "Contrarian investment, extrapolation, and risk," Journal of Finance, vol. 49, pp. 1541-1578, 1994.

[19] S. H. Sunwoo, Y. S. Yoon, H. S. Kang, S. W. Kim, W. H. Lee, and S. K. Oh, "Overreaction and Firm Specific Anomalies in the Korean Stock Market," Korea Journal of Financial Studies, vol. 17, pp. 167-218, 1994.

[20] E. F. Fama and K, R. French, "Size and book-to-market factors in earnings and returns," Journal of Finance, vol. 50, pp. 131-155, 1995

[21] R. L. Porta, J. Lakonishok, A. Shleifer, and R. Vishny, "Good news for value stocks: further evidence on market efficiency," Journal of Finance, vol. 52, pp. 859-874, 1997.

[22] H. K. Kam, "An empirical study on the performance of contrarian investment in Korea stock market," The Korean Journal of Financial Management, vol. 16, no. 2, pp. 157-178, 1999.

[23] S. P. Kim and Y. S. Yoon, "Fundamental variables, macroeconomic factors, risk characteristics and equity returns," The Korean Journal of Financial Management, vol. 16, no. 2, pp. 179-213, 1999.

[24] Y. C. Song, "The effects of size and book-to-market ratio on the cross sectional returns," Korea Journal of Financial Studies, vol. 24, pp. 83-99, 1999.

[25] W. S. Paek, "Reconciliation between book-to-market equity and earnings-price ratio through return on equity," Asia-Pacific Journal of Financial Studies, vol. 26, no. 1, pp. 119-141, 2000.

[26] S. J. Kim and J. Y. Kim, "Firm size and book-to-market factors in korean stock returns," Asian Review of Financial Research, vol. 13, no. 2, pp. 21-47, 2000

[27] K. Y. Kim and Y. B. Kim, "What determines expected stock returns in the Korean stock market?” Korea Journal of Financial Studies, vol. 28 pp. 57-84, 2001.

[28] Y. K. Chang and C. T. Kim, "A value investment strategy: its performance and sources," Korea Journal of Financial Studies, vol. 32, no. 2, pp. 165-208, 2003.

[29] B. J. Kim and P. S. Lee, "An analysis on the long-term performance of value investment strategy in Korea," Korea Journal of Financial Studies, vol. 35, no. 3, pp. 1-39, 2006.

[30] L. N. Switzer, "The behaviour of small cap vs. large cap stocks in recessions and recoveries: empirical evidence for the United States and Canada," North American Journal of Economics and Finance, vol. 21, pp. 332-346, 2010.

[31] E. F. Fama, "Market efficiency, long-term returns, and behavioral finance," Journal of Financial Economics, vol. 49, pp. 283-306, 1998.
[32] E. F. Fama and J. D. Macbeth, "risk, return, and equilibrium: empirical tests," Journal of Political Economy, vol. 81, pp. 607-636, 1973.

[33] S. A. Ross, "The arbitrage theory of capital asset pricing," Journal of Economic Theory, vol. 13, pp. 341-360, 1976.

[34] S. Hodges, "A generalization of the Sharpe Ratio and its application to valuation bounds and risk measures," FORC Preprint 98/88, University of Warwick, 1998.

[35] A. Černý, "Generalized Sharpe Ratio and consistent good deal restrictions in a model of continuous trading," Discussion Paper SWP9902/F, Imperial College Management School, 1999

[36] A. Bernardo and O. Ledoit, "Gain, loss and asset pricing," Journal of Political Economy, vol. 108, no.1, pp. 144-172, 2000.

[37] D. H. Ahn, J. Conrad, and R. F. Dittmar, "Basis assets," Review of Financial Studies, vol. 22, pp. 5133-5174, 2009.

[38] B. King, "Market and industry factors in stock price behavior," Journal of Business, vol. 39, pp. 139-190, 1966

[39] K. Daniel and S. Titman, "Evidence on the characteristics of cross sectional variation in stock returns," Journal of Finance, vol. 52, pp 1-33, 1997.

[40] M. Dahlquist and P. Söderlind, "Evaluating portfolio performance with stochastic discount factors," Journal of Business, vol. 72, pp. 347-83, 1999.

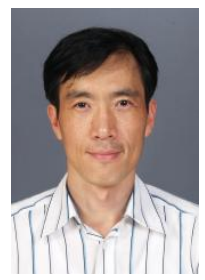

Bongjoon Kim was born in Milyang, Gyeongsang namdo, South Korea. He earned his doctoral degree in finance from Seoul National University. Currently, he is an assistant professor at Graduate School of Business Administration, Gyeongsang National University, Jinju, Gyeongsangnamdo, Korea. He had participated in Brain Korea funded by National research Foundation of Korea (NRF). His research interest includes fund evaluation by stochastic discount factors extracted parametric and nonparametric approach and market integration.

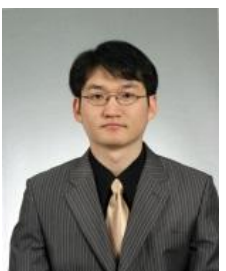

Hankyung Lee was born in Jinju, Gyeongsangnamdo, Korea. He received M.A from Gyeongsang National University and currently pursuing his Ph.D. studies in finance. He has participate in Brain Korea Plus funded by National research Foundation of Korea(NRF). His research interest includes market anomaly, nonparametric approach.

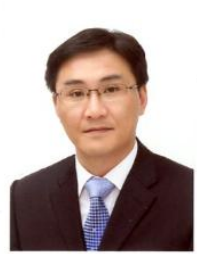

Jinsu Kim was born in South Korea. He earned his doctoral degree in finance from Kyungpook National University. Currently, he is an assistant professor at Graduate School of Business Administration, Gyeongsang National University, Jinju, Gyeongsang namdo, Korea. He has participated in Brain Korea Plus funded by National research Foundation of Korea (NRF). His research interest includes capital corporate finance, finance. structure issues (debt capacity), strategic alliance,

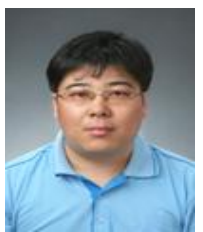

Insung Son was born in Jinju, Gyeongsangnamdo, South Korea. He received M.A from Gyeongsang National University and currently pursuing his Ph.D. studies in finance. He has participated in Brain Korea Plus funded by National research Foundation of Korea (NRF). His research interest includes capital structure issues (debt capacity) and strategic alliance. 